\title{
A BIBLIOMETRIC ANALYSIS OF THE MOST CITED ARTICLES IN GERIATRIC ANESTHESIA
}

Turkish Journal of Geriatrics

DOI: $10.31086 /$ tigeri.2020.178

2020; 23(3): 410-418

- Sibel BÜYÜKÇOBAN ${ }^{1}$ D

- Özlem ÖNER²

- Volkan $\mathrm{HANCl}^{2}$ (D)

CORRESPONDANCE

Sibel BÜYÜKÇOBAN

Dokuz Eylul University Faculty of Medicine,,

Department of Anesthesiology and Reanimation, izmir, Turkey

Phone: +905056443197

e-mail: sibelbuyukcoban@yahoo.com

Received: May 13, 2020

Accepted: Aug 12, 2020

1 Dokuz Eylul University Faculty of Medicine,

Department of Anesthesiology and Reanimation, izmir, Turkey

2 Dokuz Eylul University Faculty of Medicine,, Department of Anesthesiology and

Reanimation,Subdivision of Critical Care Medicine, İzmir, Turkey

\section{Abstract}

Introduction: The objective of this study is to evaluate the 100 most cited publications in the literature related to geriatric anesthesia in terms of bibliometric properties.

Material and Methods: After obtaining the approval of the ethical committee for this descriptive cross-sectional study, the first 100 most cited relevant publications were determined using appropriate keywords in the "advanced mode" feature of the "Institute for Scientific Information Web of Science" search engine. The data were then entered into SPSS 20.0 software program. The Kruskal Wallis test and Mann Whitney $\mathrm{U}$ test were used for the comparison of the groups.

Findings: The literature analysis conducted in this study revealed a total of 24,340 publications in the field of geriatric anesthesia over the 1975 through 2020 period.

$58 \%$ of the 100 most cited articles were published between 2000 and 2009, with a total citation average rate of $195.23 \pm 126.26$ and an annual citation average rate of $10.53 \pm 6.66 .33 \%$ of these studies were pain- related while $28 \%$ were related to cognitive functions.

$77 \%$ of journals originated from the United States and $23 \%$ from the United Kingdom.

There was a significant relationship between the publication year of the article and the total number of citations per year $(p<0.001)$.

Conclusion: The present article is the first study in the literature to evaluate the top 100 most cited studies related to geriatric anesthesia. Owing to their unique physiology that must be considered, geriatric anesthesia is also rapidly gaining ground on the path once covered by pediatric anesthesia.

Keywords: Geriatrics; Bibliometrics; Anesthesia 


\section{INTRODUCTION}

It is possible to encounter medical publications in different national and international clinical and surgical branches conducted to determine the most cited articles (1-4). When a scientific article cites another scientific article as a reference, it is defined as citing that article. The large number of scientific article citations shows the strength of the impact of a particular article. More cited scientific articles and higher-impact journals are considered higher-quality publications (2).

The first bibliographic study was published in 1987 in "The Journal of the American Medical Association (JAMA)" by Garfield under the title "The 100 Most Cited Articles Published in JAMA" (3). Since that time, a great deal of articles has been examined and presented as "the most cited articles" not only in general journals but also in specific journals $(4,5)$. While Ahmad et al. (6) identified the top 100 most cited articles in the field of bariatric surgery between 1945 and 2014, Amina et al (7) investigated the top 50 most cited articles in bariatric and endocrine surgery from 1950 to 2000. However, the number of bibliometric studies on anesthesia is quite limited. In their study, Correl et al. (8) investigated the change in academic areas of interest related to inhalation anesthetics, whereas Vlassakov et al. (9) studied local anesthetic agents. These studies shed light on clinicians and researchers to show the tendency to publish anesthesiology. The number of bibliometric studies on anesthesia is very limited. In their study, Correl et al. (8) investigated the change in academic interest in inhalation anesthetics, Vlassakov et al. (9) and local anesthetic agents. These studies shed light on clinicians and researchers to show the tendency to publish anesthesiology. On the other hand, the number of bibliometric studies on anesthesia is quite limited. In their study, Correl et al. (8) investigated the change in academic interest in inhalation anesthetics, Vlassakov et al. (9) and local anesthetic agents. These studies pave the way to show clinicians and researchers the tendency to publish articles on anesthesia.

Age could cause imbalances in human' body in an unexpected way which is a physiological process that induces changes in the functions and structure of organs, tissues and progresses with atrophy (10). In the United States (USA), 48\% of all hospital care days are dedicated to geriatric cases. At least one of every four surgical cases is at age 65 years or older (11).

The number of geriatric patients will increase in the next two decades. Therefore, it is essential for every anesthetist to know geriatric anesthesia well, to follow the future of developments and studies. The most significance three parts for geriatric surgery are appropriate anesthesia techniques, preoperative examination of the patient cautiously, optimum personalized surgical method (12). Bibliometric studies may be a guiding light in geriatric anesthesia as in other areas where they are applicable. It is possible to access the database as well as valuable information such as academic personal citation statistics and mean citation indexes by using the Web of Science search engine $(1,13,14)$. The objective of this study is to examine the most frequently cited internationally published articles on geriatric anesthesia scanned through the Institute for Scientific Information (ISI) Web of Science (WOS) search engine with respect to authors, countries and institutions, and to analyze which journals these articles were publihed through a bibliometric analysis.

\section{MATERIAL AND METHOD}

The study, planned as a descriptive cross-sectional study, was conducted using the "advanced mode" feature of the ISI and WOS search engine after obtaining the approval of the ethics committee (Decision no: 5316-GOA 2020/05-19). The appropriate search keys were used. (These key words are in adnex 1) The scan was conducted on with the inclusion all articles published from 1975 to January 2020. The 100 most cited publications 
among internationally published articles on geriatric anesthesia were determined and listed. The contents of the articles were reviewed one by one by the first author. Topics related to geriatric anesthesia, specialties of the authors as well as journals in which they were published were recorded. The total number of citations for each publication, the number of citations per year, authors, information related to the study and the journal were all determined using WOS. Articles with sections such as letter to the editor, case study and poster presentation were excluded from the study.

\section{Statistical Analysis}

Statistical analyses of the data obtained in the research were entered into the SPSS (Statistical Package for Social Sciences, Chicago, IL, USA) 20.0 program and the entered data were then analyzed. The Kruskal Wallis test and Mann Whitney $U$ test were used for the comparison of the groups. The statistical method used to investigate the significance of the difference between groups is shown in Table 1. A p value below 0.05 was regarded as a significant difference.

\section{RESULTS}

It was found that there were 24,340 publications in the WOS search engine over the 1975 through January 2020 period. While the most cited study had 693 citations, the lowest number of citations among the top 100 most cited studies was 95 . The distribution of the 100 most cited articles in the field of geriatric anesthesia according to the number of articles cited by the first authors is shown in adnex 2. The average number of citations of the 100 most cited studies was established as $195.23 \pm 126.26$. The annual citation rates of the studies ranged from 31.50 to 2.84 , and the mean was found to be $10.53 \pm 6.66$.

The most cited study is "Influence of age and gender on the pharmacokinetics and pharmacodynamics of remifentanil .1. Model development" published by Minto, CF et al. in 1997 in the journal of "ANESTHESIOLOGY".

An examination of the top 100 most cited studies in the field of geriatric anesthesia revealed that the first three areas were pain (33\%), cognitive functions (28\%) and out-come (16\%), respectively. The first three journals with the most top-100 publications were "ANESTHESIOLOGY" (21\%), "PAIN" (20\%), "BRITISH JOURNAL OF ANAESTHESIA" (12\%), respectively.

$84 \%$ of the 100 most cited articles in the field of geriatric anesthesia were in $\mathrm{SCl}$ (Science Citation Index) and 16\% in journals indexed in $\mathrm{SCl}-\mathrm{E}$ (Science Citation Index Expanded). The distribution of the articles in terms of $\mathrm{Q}$ indexes was Q1 65\%, Q2 28\%, Q3 6\%, Q4 1\% respectively.

The authors' country of origin was $50 \%$ United States, 38\% European countries, 5\% Canada and $7 \%$ other countries. $77 \%$ of journals originated from the United States and 23\% from the United Kingdom. The respective top 100 most cited articles in geriatric anesthesia are shown in adnex 2.

$58 \%$ of the 100 most cited articles in the field of geriatric anesthesia were published between 2000 and 2009 (Graphic 1).

There was a significant relationship between the publication year of the article and the number of citations per year $(p<0.001)$. The author's country of origin, the country of the journal and the index of the journal were found to have no significant relation with the total and annual citations rates ( $p>0.05$ ). The distribution of the articles according to their characteristics is presented in Table 1.

The specialties of the first authors of the articles were $45 \%$ anesthesia, $11 \%$ geriatrics, $10 \%$ psychiatry, 10\% algology, 3\% internal medicine, and $22 \%$ other branches, respectively. Of the 100 most cited studies in geriatric anesthesia, $43 \%$ were randomized controlled trials, $21 \%$ 
Table 1. The Characteristics of the 100 Most Cited Articles about Geriatric Anaesthesia in the Literature.

\begin{tabular}{|c|c|c|c|c|c|c|}
\hline & Subgroups & $N$ & $\begin{array}{l}\text { Overall Citation } \\
\text { Number } \\
\text { mean } \pm \text { SD }\end{array}$ & $\begin{array}{l}\text { Annual Citation } \\
\text { Number } \\
\text { mean } \pm \text { SD }\end{array}$ & $\begin{array}{l}\text { p Value } \\
\text { (Overall Citation } \\
\text { Number) }\end{array}$ & $\begin{array}{l}\text { p value } \\
\text { (Annular Citation } \\
\text { Number) }\end{array}$ \\
\hline Year $^{1}$ & $\begin{array}{l}<1990 \\
1991-1994 \\
1995-1999 \\
2000-2004 \\
2005-2009 \\
2010-2014 \\
\end{array}$ & \begin{tabular}{|l}
12 \\
6 \\
16 \\
32 \\
26 \\
8 \\
\end{tabular} & $\begin{array}{l}168,33 \pm 81,04 \\
279,66 \pm 150,88 \\
268,81 \pm 210,57 \\
158,25 \pm 94,94 \\
175,11 \pm 103,54 \\
157,12 \pm 38,86\end{array}$ & $\begin{array}{l}4,75 \pm 2,22 \\
9,87 \pm 5,39 \\
11,51 \pm 9,17 \\
9,40 \pm 5,05 \\
11,80 \pm 6,43 \\
18,13 \pm 4,62 \\
\end{array}$ & 0,326 & $<0,001$ \\
\hline $\begin{array}{l}\text { Journal } \\
\text { Index }\end{array}$ & $\begin{array}{l}\mathrm{SCl} \\
\mathrm{SClE}\end{array}$ & $\begin{array}{l}84 \\
16\end{array}$ & $\begin{array}{l}190,17 \pm 126,32 \\
221,75 \pm 126,61\end{array}$ & $\begin{array}{l}11,00 \pm 5,63 \\
10,44 \pm 6,87\end{array}$ & 0,608 & 0,541 \\
\hline Journal $\mathbf{Q}^{1}$ & $\begin{array}{l}\mathrm{Q} 1 \\
\mathrm{O} 2 \\
\mathrm{Q} 3 \\
\mathrm{Q} 4\end{array}$ & $\begin{array}{l}65 \\
28 \\
6 \\
1\end{array}$ & $\begin{array}{l}200,04 \pm 139,53 \\
186,85 \pm 104,54 \\
174,50 \pm 76,27 \\
241,00\end{array}$ & $\begin{array}{l}10,65 \pm 7,04 \\
10,70 \pm 6,27 \\
8,70 \pm 5,25 \\
8,61\end{array}$ & 0,772 & 0,948 \\
\hline $\begin{array}{l}\text { Journal } \\
\text { Type }^{1}\end{array}$ & $\begin{array}{l}\text { Anesthesia } \\
\text { Pain } \\
\text { Geriatrics }\end{array}$ & $\begin{array}{l}55 \\
33 \\
12\end{array}$ & $\begin{array}{l}197,03 \pm 137,67 \\
208,39 \pm 125,18 \\
150,75 \pm 46,40\end{array}$ & $\begin{array}{l}10,80 \pm 7,49 \\
11,19 \pm 6,10 \\
7,47 \pm 1,95\end{array}$ & 0,557 & 0,222 \\
\hline $\begin{array}{l}\text { EU or } \\
\text { non-EU } 2\end{array}$ & $\begin{array}{l}\text { Europa } \\
\text { Non-Europa }\end{array}$ & $\begin{array}{l}38 \\
62\end{array}$ & $\begin{array}{l}214,23 \pm 131,91 \\
183,58 \pm 122,29\end{array}$ & $\begin{array}{l}11,06 \pm 6,92 \\
10,20 \pm 6,53\end{array}$ & 0,241 & 0,535 \\
\hline $\begin{array}{l}\text { Authours' } \\
\text { Nationalities }^{1}\end{array}$ & $\begin{array}{l}\text { USA } \\
\text { Canada } \\
\text { Europa } \\
\text { Other }\end{array}$ & $\begin{array}{l}50 \\
5 \\
38 \\
7\end{array}$ & $\begin{array}{l}180,40 \pm 118,63 \\
170,20 \pm 96,45 \\
214,23 \pm 131,91 \\
215,85 \pm 171,67\end{array}$ & $\begin{array}{l}9,98 \pm 6,23 \\
8,31 \pm 3,45 \\
11,06 \pm 6,92 \\
9,77 \pm 10,53\end{array}$ & 0,183 & 0,885 \\
\hline
\end{tabular}

1. Kruskal-wallis test.

2. Mann withney-U test.

were prospective, $10 \%$ were compiled, $7 \%$ were retrospective, $6 \%$ were analytical cross-sectional studies, and the remaining $5 \%$ were meta-analyses.

While anesthesiologists and algologists mostly publish their articles in journals related to their own fields, psychiatrists predominantly publish articles in journals related to pain. Geriatric specialists were found to be publishing articles also in journals related to various other areas of medicine led by pain. When research subjects in the field of geriatric anesthesia are examined, it can be seen that pharmacology was studied at a greater scale in the 1990s, and then subject selection inclined towards pain between 2000 and 2009 (Graphic 2).

As hip fractures are the most common cases of geriatric anesthesia in the operating room, an examination of the articles in terms of hip fracture revealed that the studies examining hip fracture patients in these articles was found to be $14 \%$. Articles that did not examine hip fracture cases focused on pain (32\%), cognitive functions (23\%) and outcome (10\%), respectively (Table 2 ).

\section{Discussion}

Our study, which examines the citation rates of international articles on geriatric anesthesia, is the first study in this context. In the present study, we 
Table 2. Topic Distribution of the Subjects Related to Hip Fracture Patients in the First 100 Most Cited Articles in Geriatric Anesthesia

\begin{tabular}{|l|l|l|l|l|}
\hline \multirow{2}{*}{ Hip Fracture } & \multicolumn{4}{|c|}{ Articles Subjects } \\
\cline { 2 - 5 } & Pain & Cognitive & Outcome & Other \\
No. (\%)* & No. (\%) & No. (\%)* & No. (\%) \\
\hline Hip fracture - & $32(37,2)$ & $23(26,7)$ & $10(11,6)$ & $21(14,3)$ \\
\hline Hip fracture + & $1(7,1)$ & $5(35,7)$ & $6(42,9)$ & $2(14,3)$ \\
\hline Total & $33(33,0)$ & $28(28,0)$ & $16(16.0)$ & $23(23.0)$ \\
\hline
\end{tabular}

* percentage of row

examined the most cited internationally sourced articles on geriatric anesthesia using the ISI and WOS search engines, reviewed these articles by authors, countries of origin and institutions, and evaluated journals in which they were published.

It is a fact that some bibliometric studies have been conducted in various disciplines on a worldwide and national basis, but there are very few bibliometric studies in the international literature in the field of anesthesiology (13).

The present study showed that the first three journals with the most frequently cited publications in the field of geriatric anesthesia were "ANESTHESIOLOGY" (21\%), "PAIN" (20\%), "BRITISH JOURNAL OF ANAESTHESIA" (12\%) respectively, whereas $77 \%$ of journals originated from the United States and 23\% from the United Kingdom. Also, $50 \%$ of the authors of the articles are of US origin.

Bould et al. (15) reviewed articles on anesthesia, intensive care and pain that were published in $\mathrm{SCl}$ journals between 1997 and 1998. They reported that the United States published more original articles than any other country and articles from high-income countries were likely to be more frequently published than middle-income countries, notably Turkey, China and India. The journal in which Bould et al. made this publication is "Anesthesia", a UK-based journal. Britain is the second country in the world, after the USA, to dominate the geriatric anesthesia literature. In a bibliometric analysis conducted by Yilmaz et al (16), the authors evaluated the scientific performance of publications in the field of general anesthesia in Turkey as well as on a global basis. According to the results of that study, the total number of publications in Turkish-based anesthesia journals displayed a significant decline between 2004 and 2009. However, they observed that the publication rate increased again after 2009. The study established that the first five countries with most publications in the field of anesthesiology included developed countries like the USA, the UK, Germany, France and Canada, whereas Turkey ranked 14 th in the world.

The most remarkable feature of the most cited article in our study, conducted by Minto et al. and published in 1997, is that it highlights accurate dose management of short-acting opioids in geriatric anesthesia, such as widely-used remifentanil (17). Although published in 2014, the most recent publication in our list, which could quickly enter the list of top 100 articles with an annual rate of 22.5 citations, belongs to Griffiths R.et al. In that publication, which highlighted the significance of geriatric anesthesia, it was reported that the elderly were at relatively higher risk compared with young surgical patients in terms of mortality and morbidity following elective and (especially) emergency surgery, which is a proof of the demand for such publications in this field. (18).

Journals that basically address scientific issues publish studies evaluating citation indexes and publication quality on a variety of topics. The high number of citations scientific articles receieve does not necessarily reflect the relevant strength of that article on a particular topic. The most commonly used indicators in the evaluation of scientific 
Figure 1. The Distribution of the Most Cited Articles by Year

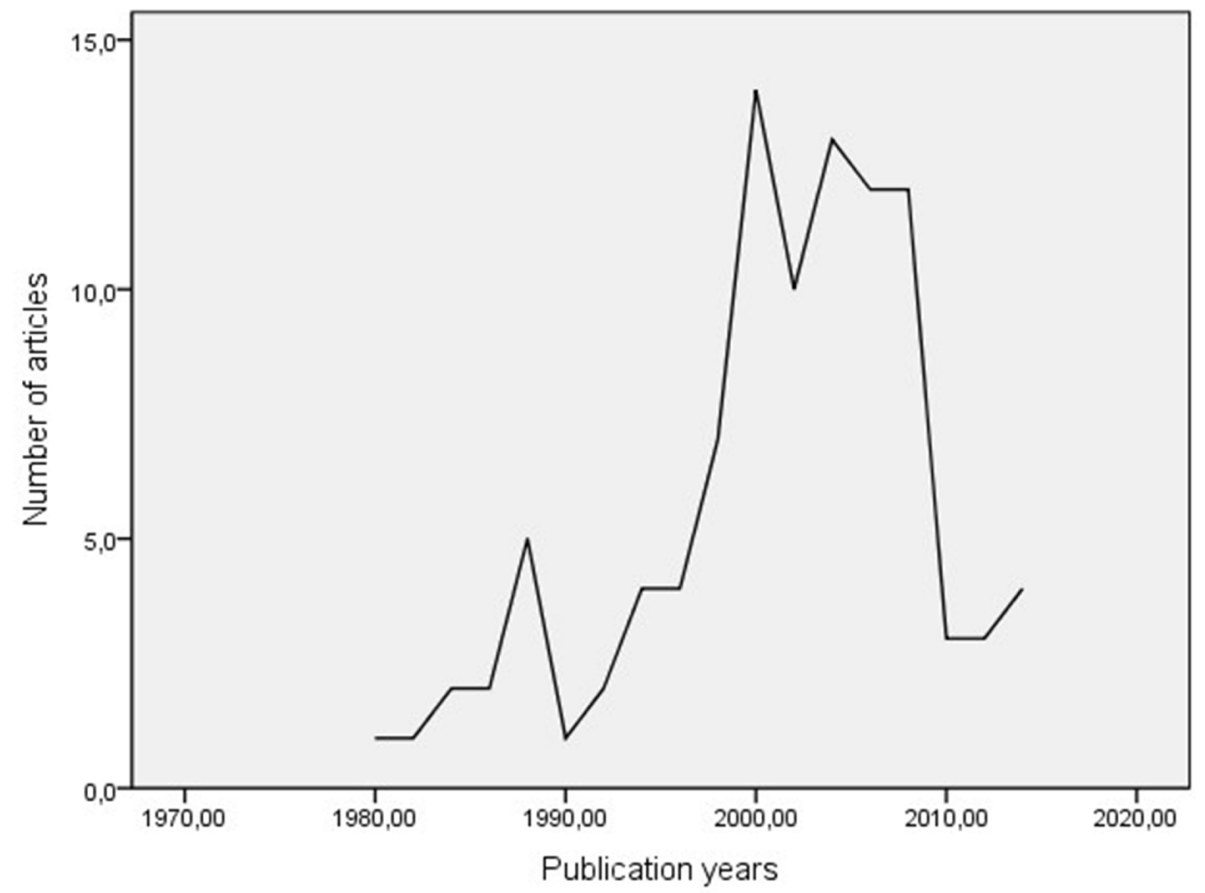

Figure 2. The Distribution of Subject Areas of the Top 100 Articles Cited in Geriatric Anesthesia by Year

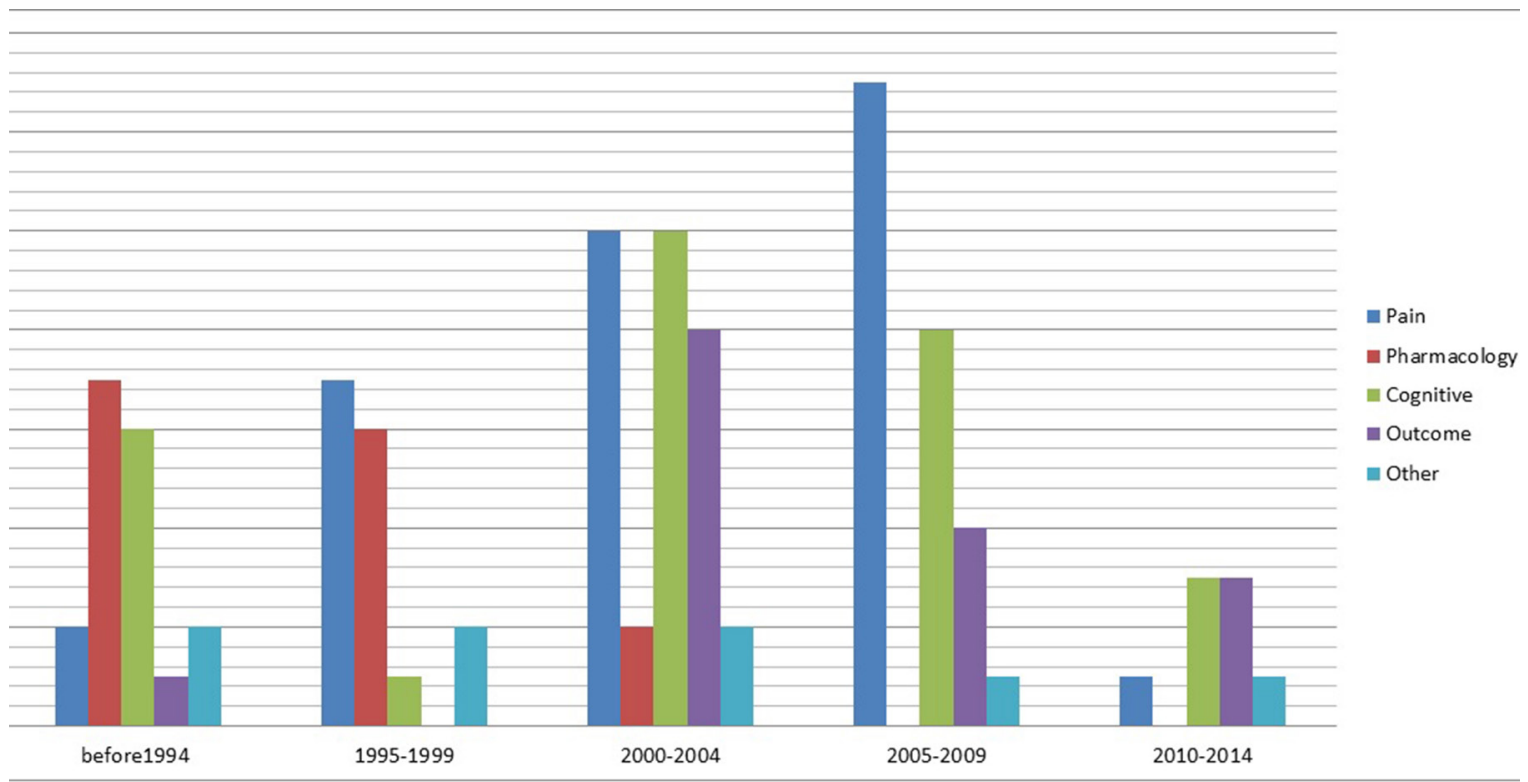


journals include the number of citations and the average by years. Although more frequently cited scientific articles and journals are accepted more scientifically efficient, there is also a limit to these indicators. In a study they carried out in 2017-2018, Mchugh et al. (19) analysed 12,544 citations on the WOS citation index published by 12 anesthetic journals in 2016 and found the median number of citations made per item as 3.3 (2.6-4.1). Their analysis may provide information to authors and editors on issues such as where to submit work, what editorial policy to pursue and what journal strategy to follow, respectively.

In a study they carried out in 2013, Yoon et al. (20) identified the top-cited articles in the field of radiology between 1945 and 2012. These articles were then classified among themselves as neuroradiology, interventional radiology, breast imaging and ablation of hepatic tumors. In our study, an examination of the 100 top-cited studies in the field of geriatric anesthesia revealed that the first three areas were pain (33\%), cognitive functions (28\%) and out-come (16\%), respectively.

In a study conducted in the field of anesthesiology and intensive care in Scandinavian countries as well as the UK (21), the number of publications in annual journals between 1981 and 2000 was examined during the 20-year period in Sweden, Norway, Finland and Denmark. For comparison, data from the UK were also analyzed. It was reported that there was a significant increase in Finland and Norway compared to other countries during this period, and the percentage of cited papers in these countries also increased in the last 20 years. In our study, it was found that the period during which the most cited studies in the field of geriatric anesthesia was conductesd was the years from 2000 to 2009 (58\%). However, it was observed that this rate declined by $8 \%$ over the period 2010-2014. Nevertheless, in order to be among the top 100 in the number of citations, it is necessary to surpass the citation rate of studies that receive citations in previous years, so we believe that the publications should not be considered to be declining after 2009. The study conducted by Cheng et al (13) can help us better understand the contribution of anesthesiology research activities to the world over the past 20 years. The authors examined a total of 64,199 articles published from 1995 to 2014, with 1,084,491 cited times. The total number of articles published by journals showed a slight increase in the second decade. Over 45\% of these articles were published by the top five journals that have maintained their ranking over 20 years. It was found that most publications originated from North America and European countries, of which the United States had the highest number of publications and citations. Most of the institutions are academic universities and hospitals. More than half of the top 25 institutions (in rankings) are located in the United States, and Harvard University accounted the highest number of articles and citations among all institutions.

Like pediatric cases, geriatric anesthesia, too, has sensitive aspects that make them unique and require more evaluation and attention. The geriatric age group also has a unique physiology that must be considered. Even with these accompanying comorbidities, traumas experienced and adaptation mechanisms, this physiology may display a wider spectrum than pediatric anesthesia. Results for pediatric patients undergoing anesthesia have improved over the years thanks to improvements in monitoring and equipment, safer and more easily titratable anesthetic agents, and possibly the practice of sub-specialization (22). Geriatric anesthesia has been progressing over the years on the way to be practiced by anesthesiologists specially educated for the care of the elderly, just like pediatric anesthesiologists.

When research subjects in the field of geriatric anesthesia are examined, it can be seen that pharmacology was studied at a greater scale in 
the 1990s, and then the subject selection inclined towards pain between 2000 and 2009. While anesthesiologists and algologists mostly publish their articles in journals related to their own fields, psychiatrists predominantly publish articles in pain-related journals. It was found that geriatric specialists were publishing articles also in journals related to various other areas of medicine led by pain.

The most important limitation of our study is the fact that the search keys are determined by the WOS search engine itself. Consequently, some related studies cannot be included in the list

\section{REFERENCES}

1. Usta $Y Y$, Demir $Y$, Yönder $M$, Yildiz A. Nursing students' attitudes toward ageism in Turkey. Arch Gerontol Geriatr 2012;54(1):90-3. (PMID: 21353316)

2. Bakirhan S, Ozkeskin M, Reyhanioglu Da, Gulpinar D. Analysis of The Attitudes and Approaches of the Physiotherapy and Rehabilitation Students Towards the Elderly. Turkish Journal of Geriatrics 2017;20(2):125-134

3. Turgay AS, Sahin S, Aykar FS, SariD, Badir A, Ozer C. Attitudes of Turkish nursing students toward elderly people. European Geriatric Medicine 2015;6(3):267270.

4. Wood K, Gibson F, Radley A, Williams B. Pharmaceutical care of older people: what do older people want from community pharmacy? Int J Pharm Pract 2015;23(2):121-30. (PMID: 24905628)

5. Leung S, Logiudice D, Schwarz J, Brand C. Hospital doctors' attitudes towards older people. Intern Med J. 2011;41(4):308-14. (PMID: 20002850)

6. Williams D, Bennett K, Freely J. Evidence for an age and gender bias in the secondary prevention of ischemic heart disease in primary care. $\mathrm{Br} \mathrm{J}$ Clin Pharmacol. 2003;55(6);604-608. (PMID: 12814456)

7. Gunderson A, Tomkowiak J, Menachemi N, Brooks R. Rural physicians' attitudes toward the elderly: evidence of ageism? Q Manage Health Care 2005;14(3):167-76. (PMID: 16027595)

8. Lui NL, Wong CH. Junior Doctors' Attitudes Towards Older Adults and its Correlates in a Tertiary-care Public obtained at the end of the search. However, this rate is very low and is not only true for this study. In fact, all studies addressing this subject have the same limitations.

As a result, bibliographic writings created by using scientific search engines have a guiding role in determining where to focus in scientific research. It is recommended that such studies are updated and rewritten at certain time intervals in order to perform a substantial data analysis.

Hospital. Ann Acad Med Singapore 2009;38(2):125-9. (PMID: 19271039)

9. Meisner BA. Physicians' attitudes toward aging, the aged, and the provision of geriatric care: a systematic narrative review. Critical Public Health 2012;22(1):6172.

10. Beecham L. Age concern survey shows ageism in NHS (Medicopolitical digest). Br Med J 2000; 320(7247):1479. https://doi.org/10.1136/ bmj.320.7247.1479

11. Helton MR, Pathman DE. Caring for older patients: current attitudes and future plans of family medicine residents. Fam Med 2008;40(10):707-14. (PMID: 18979258)

12. Michielutte, R, Diseker, RA. Health care providers' perceptions of the elderly and level of interest in geriatrics as a specialty. Gerontol Geriatr Educ. 19841985;5(2):65-85. (PMID: 6537370)

13. Sahin S, Mandiracioglu A, Tekin N, Senuzun F, Akcicek F. Attitudes toward the elderly among the health care providers: Reliability and validity of Turkish version of the UCLA Geriatrics Attitudes (UCLA-GA) scale. Arch Gerontol Geriatr. 2012 Jul-Aug;55(1):205-9. (PMID: 21937128)

14. Doherty M, Mitchell EA, O'Neill S. Attitudes of healthcare workers towards older people in a rural population: A survey using the Kogan Scale. Nurs Res Pract. 2011;2011:352627. (PMID: 21994823)

15. Hughes NJ, Soiza RL, Chua M, et al. Medical student 
attitudes toward older people and willingness to consider a career in geriatric medicine. J Am Geriatr Soc 2008;56(2):334-8. (PMID: 18179490)

16. Kishimoto $M$, Nagoshi $M$, Williams $S$, Masaki $\mathrm{KH}$, Blanchette PL. Knowledge and attitudes about geriatrics of medical students, internal medicine residents, and geriatric medicine fellows. J Am Geriatr Soc 2005;53(1):99-102. (PMID: 15667384)

17. Ozer ZC, Terkes N. Evaluation of Nursing Student's Attitudes Towards Ageism in Turkey. Procedia-Social and Behavioral Sciences 2014;116:2512-2515

18. Kalayci I, Yazıcı SO, Ozkul M, Helvaci G. Attitudes of Medical Staff And Students Towards The Elderly: Systematic Review. Adnan Menderes University Journal of Faculty of Health Sciences 2018;2(1):21-30. In Turkish

19. Wilson MA, Kurrle SE, Wilson I. Understanding Australian medical student attitudes towards older people. Australas J Ageing. 2018 Jun;37(2):93-98. (PMID: 29333700)

20. Kalaycı I, Ozkul M, Ozbek Yazıcı S, Kupeli A. The Unseen Side of Neglect And Abuse: The Importance of Assistant Personnel Education in Health Services As A Precaution Against Elder Abuse And Neglect.
The Journal of Social Science 2017;4(11):576-593. In Turkish

21. Hobbs C, Dean CM, Higgs J, Adamson B. Physiotherapy students' attitudes towards and knowledge of older people. Aust J Physiother 2006;52(2):115-9. (PMID: 16764548)

22. Cankurtaran $M$, Halil M, Ulger $Z$, et al. Influence of medical education on students' attitudes towards the elderly. J Natl Med Assoc 2006;98(9):1518-22. (PMID: 17019923)

23. Caliskan T, Kendir C, Tekin N, Kartal M. Attitudes toward the elderly among young family physicians in Turkey. J Family Med Prim Care 2018;7(5):998-1001. (PMID: 30598946)

24. Lee M, Reuben DB, Ferrell BA. Multidimensional attitudes of medical residents and geriatrics fellows toward older people. J Am Geriatr Soc 2005;53 (3): 489-494. (PMID: 15743295)

25. Fitzgerald JT, Wray LA, Halter JB, Williams BC, Supiano MA. Relating medical students' knowledge, attitudes, and experience to an interest in geriatric medicine. Gerontologist 2003;43(6):849-55. (PMID: 14704384) 